\title{
Purity and structural composition of lignin isolated from Miscanthus $x$ giganteus by sub-critical water extraction with associated modifiers
}

\author{
Muhammad Hazwan Hamzaha,b,c*, Steve Bowrad, Philip Cox
}

aDepartment of Biological and Agricultural Engineering, Faculty of Engineering, Universiti Putra Malaysia, 43400 Serdang, Selangor, Malaysia;

${ }^{b}$ SMART Farming Technology Research Centre, Faculty of Engineering, Universiti Putra Malaysia, 43400 Serdang, Selangor, Malaysia;

cSchool of Chemical Engineering, University of Birmingham, Edgbaston B15 2TT, United Kingdom;

dPhytatec (UK) Ltd., Plas Gogerddan, Aberystwyth SY23 3EB, United Kingdom;

${ }^{e}$ Chemical Engineering, University of Wolverhampton, Wulfruna Street, Wolverhampton WV1 1LY, United Kingdom

\begin{tabular}{|c|c|}
\hline ARTICLE HISTORY & Abstract \\
\hline $\begin{array}{l}\text { Received: } 24 \text { March } 2020 \\
\text { Received in revised form: } 6 \text { April } \\
2020 \\
\text { Accepted: } 11 \text { April } 2020 \\
\text { Available Online: } 15 \text { April } 2020 \\
\text { Keywords } \\
\text { Miscanthus } \\
\text { Lignocellulosic biomass } \\
\text { Lignin } \\
\text { Sub-critical water } \\
\text { Modified organosolv }\end{array}$ & $\begin{array}{l}\text { Lignin is an industrial by-product produced from the pulping and paper industry, where the } \\
\text { process generates lignin in the form of lignosulphonates. While there are many applications } \\
\text { for lignin, there are all low value and attempts to add value to lignin are hindered by its } \\
\text { complex physicochemical nature and the presence of sulphur. Adopting the biorefining } \\
\text { concept, the study evaluates the impact of direct (DE) and sequential extraction (SE) of } \\
\text { Miscanthus x giganteus using sub-critical water with associated modifiers; ethanol and carbon } \\
\text { dioxide on the physical and chemical properties of the extracted lignin. Isolated lignins were } \\
\text { characterised by a Fourier Transform Infrared Spectroscopy (FTIR). Although higher } \\
\text { delignification was achieved by DE and SE about } 81.5 \% \text { and } 58.0 \% \text {, respectively, the lignin } \\
\text { recovered from the SE process showed remarkably higher purity with } 91.5 \% \text {. Lignin recovery } \\
\text { did not differ considerably for either processing method. FTIR revealed a qualitative reduction } \\
\text { in the intensity of bonds corresponding to hydroxyl groups for the lignin derived from DE } \\
\text { rather than SE processing routes. These indicated that the lignin derived from SE had potential } \\
\text { for subsequent preparation in lignin value-added bio-based materials. }\end{array}$ \\
\hline
\end{tabular}

\section{Introduction}

Lignin is amongst the most abundant natural polymers on earth, second only to cellulose. Lignin is found in all terrestrial plants and some aquatic species. Currently, the biosphere contains approximately $3 \times 10^{11}$ tonnes of lignin with a $2 \times 10^{10}$ tonnes annual biosynthetic production rate (Ganewatta et al., 2019). Currently, lignin is produced in large quantities as a byproduct from pulping industry and this amount will increase as lignocellulosic ethanol production is developed (Ten and Vermerris, 2015). Sulphur lignins such as Kraft and lignosulfonates are mainly produced by chemical pulping process in the form of black liquor, leaving cellulose fibers for pulp production. Both lignins either from Kraft and sulphite pulping recovered from black liquor by acidified process. Lignosulphonates contains sulfonic acid groups that makes lignin water soluble. Lignosulphonates are relatively high molecular weight than Kraft lignin with a broad distribution of polydispersity index (around 6-8) and lignosulphonates are the most utilised lignins for few industrial applications including dispersant, binders and packaging additives (Laurichesse and Avérous, 2014). Recently, sulphur-free lignins such as organosolv lignin also has been explored attributed to its high purity, high solubility in organic solvents, hydrophobic and a low macromolecular size after fractionation steps (Matsushita, 2015). The organosolv lignin also had an advantage of environmental applications due to the organosolv lignin does not contain sulphur and suitable for chemical modification ( $\mathrm{Li}$ and Takkellapati, 2019).

In this context, the research presented focuses on lignin extraction from Miscanthus $x$ giganteus (MxG) using sub-critical water (SCW) with associated modifiers. The method of SCW applied in conjunction with the proposed modified organosolv method. The organosolv process uses organic or aqueous organic solvent mixtures with inorganic acid catalysts such as hydrochloric and sulphuric acids on lignin extraction process from lignocellulosic biomass (Ouyang et al., 2018). Here, the proposed modifiers used to include the utilisation of ethanolwater mixture in SCW, and addition of carbon dioxide $\left(\mathrm{CO}_{2}\right)$ under pressure that create carbonic acid which serve as catalyst for hydrolysis reaction (Morais et al., 2015). In addition, the $\mathrm{CO}_{2}$ is more environmental friendly than concentrated acids used in the SCW process due to $\mathrm{CO}_{2}$ is non-toxic, non-flammable and low cost (Attard and Hunt, 2018). Due to the low polarity of $\mathrm{CO}_{2}$, ethanol was used as the polar co-solvent because of its lower toxicity compared to other polar co-solvents. This was added to enhance the compounds' solubility in the SCW (Manjare and Dhingra, 2019). The utilisation of $100 \%$ ethanol was not preferred for delignification due to the unavailability of nucleophilic agents. The modified organosolv method used an ethanol-water mixture as the organic solvents. The ethanol was recovered by distillation-based (Roque, 2013). With the addition of water, the nucleophilic agent stimulated the cleavage of the lignin but decreased the capability of the solvent to dissolve the lignin in the delignification process (Pasquini et al., 2005). A previous study found that a 1:1 ethanol-water mixture achieved optimal delignification (Roque et al., 2012).

The application of SCW associated with organosolv treatments have been reported in the literature. Huijgen et al. (2012) recovered lignin from wheat straw prior to cellulose enzymatic hydrolysis. They conducted SCW treatment in water acidifed with $\mathrm{H}_{2} \mathrm{SO}_{4}$ in an autoclave reactor with a regime of temperatures between 160 to $190^{\circ} \mathrm{C}$, a reaction time between 30 to 120 minutes to hydrolyse hemicellulose followed by the 
organosolv method. The organosolv method (ethanol-water mixtures) was carried out using conditions of temperature between 190 to $220^{\circ} \mathrm{C}$ and a reaction time of 60 minutes. Hage et al. (2010) examined the effect of first step pretreatment using SCW and followed by organosolv method in ethanol-water solution of $M x G$. The results demonstrated that an increase in temperature of SCW process from 130 to $150^{\circ} \mathrm{C}$ affected the lignin structure for the subsequent organosolv delignification at $170^{\circ} \mathrm{C}$, whereby the SCW process could enhance the lignin fragmentation and foster re-polymerisation reactions. Amendola et al. (2012) used a two-step process: SCW pretreatment at $180^{\circ} \mathrm{C}$ for 30 minutes followed by ethanol organosolv at $180^{\circ} \mathrm{C}$ for 90 minutes for hemicelluloses and lignin recovery from red grape stalks. The results suggest that an autohydrolysis milder treatment $\left(180^{\circ} \mathrm{C}\right)$ helped to hydrolyse hemicellulose, whereas the organosolv process did not give a consistent delignification depending on lignin precipitation steps by addition of acetic acid before or after the organosolv pretreatment. All of the studies reviewed here support the hypothesis that a combination of SCW with organosolv could be an appropriate method to recover lignin from different materials.

In this study, SCW was applied at pressures up to 50 bar and at temperature ranges of $120^{\circ} \mathrm{C}$ to $200^{\circ} \mathrm{C}$, depending on the targeted components to recover (Kalnins, 2017; Roque, 2013). Temperature has a pronounced influence on the conversion rate of the lignocellulosic biomass in SCW hydrolysis. A three-stage pretreatment was suggested within the research group to recover the major components of the lignocellulosic biomass. A first and second stage was conducted to remove extractives including non-structural compounds and to recover hemicellulose at the lowest extraction severity $\left(120^{\circ} \mathrm{C}\right)$ and at low to medium extraction severity $\left(180^{\circ} \mathrm{C}\right)$, respectively via the SCW process (Kalnins, 2017). The final stage was performed at the highest severity $\left(200^{\circ} \mathrm{C}\right)$ in which organic solvents, such as ethanol, were added to the SCW to remove the lignin, a hydrophobic polymer, from the solid fraction and yield cellulose-enriched fibres. The remaining cellulose-enriched fibres were then used for cellulose-based applications within the research group (Barros, 2016; Muniz et al., 2018).

This study evaluated the impact of processing $M x G$ in two different routes towards delignification: (1) $M x G$ was delignified via direct SCW, which yielded lignin-and hemicellulose-enriched soluble fractions; and (2) $M x G$ was subjected to a sequential SCW mediated hydrolysis, which yielded lignin-enriched soluble fractions. The specific objective of this work was to compare the purity and chemical properties of lignin extracted from the two different processing routes.

\section{Materials and methods}

\subsection{Materials}

The $M x G$ was grown and harvested in Aberystwyth, Wales, UK, and provided by the Institute of Biological, Environmental and Rural Sciences (IBERS, Aberystwyth, UK) and Phytatec Ltd (Aberystwyth, UK). The biomass was stored in a dry and dark place. Nitrogen (compressed oxygen free nitrogen, BOC, UK), and carbon dioxide (vapour withdrawal, BOC, UK) had $\geq 99.8 \%$ purity. $72 \%$ sulphuric acid (Fluka-Sigma Aldrich, UK) and absolute ethanol (Fisher Scientific, UK) were used as reagents.

\subsection{Direct and sequential lignin extraction}

The $M x G$ was treated through a three-stage temperature profile sequential batch extraction (SE) to differentially separate extractives, hemicellulose, cellulose, and lignin. The first step applied SCW at $120^{\circ} \mathrm{C}$ with an equilibrium time of 30 minutes and 50 bar of nitrogen gas to remove water-soluble extractives that could have interfered with the isolation and later analytical steps. The second step used a SCW at a regime of $180^{\circ} \mathrm{C}$ and a reaction time of 30 minutes under 50 bar of nitrogen gas to hydrolyse hemicelluloses prior to delignification. The final step involved lignin extraction via a SCW with associated modifiers using a $1: 1$ ethanol-water mixture at $200^{\circ} \mathrm{C}$, a reaction time of 60 minutes, and 50 bar of carbon dioxide gas. For DE, the $M x G$ was subjected to a single treatment step, which was similar to the third treatment in SE, by the SCW with associated modifiers.

\subsection{Biomass preparation}

Prior to hydrolysis, the $M x G$ was mixed in distilled water then warmed to $50^{\circ} \mathrm{C}$ to soften the grass. The mixture was then soaked for 20 minutes to rehydrate the grass. The mixture was milled for 3 minutes in a domestic blender to reduce the particle size of the material. The grinding conditions of the temperature, soaking time, grinding time, and the solid-to-liquid ratio were previously optimised to yield an average particle size of $500 \mu \mathrm{m}$ (Roque, 2013).

The $M x G$ slurry was placed inside the reactor directly after the sample preparation for $\mathrm{SE}$ at $120^{\circ} \mathrm{C}$. The sequentially processed $M x G$ obtained at $120^{\circ} \mathrm{C}$ was used for biomass hydrolysis at $180^{\circ} \mathrm{C}$ and $200^{\circ} \mathrm{C}$. The sequentially processed $M x G$ was mixed in water and a $1: 1$ ethanol-water solution for $180^{\circ} \mathrm{C}$ and $200^{\circ} \mathrm{C}$, respectively by warming to $50^{\circ} \mathrm{C}$ and a wetting time 5 minutes prior to each hydrolysis step. The $M x G$ preparation conditions for DE were a 1:1 ethanol-water solution warmed to $50^{\circ} \mathrm{C}$ with a soaking time of 20 minutes prior to delignification.

\subsection{Biomass hydrolysis}

The $M x G$ slurry was transferred to a $500 \mathrm{~mL}$ stirred pressure vessel (Alloy C276, Parr, IL, USA). The reactor was closed and pressurised with desired gas to 50 bar. The set point temperature was increased to the set temperature and was kept stable during the reaction time by a controller (4386, Parr). After the reaction, the reactor temperature was decreased through a cooling system with a cooling coil inside the pressure vessel in which a coolant flew at an initial $-7^{\circ} \mathrm{C}$. When the temperature fell below $50^{\circ} \mathrm{C}$, the reactor was depressurised slowly to atmospheric pressure before the reactor was opened. Finally, the solid fibres were filtered and dried to constant mass at $65^{\circ} \mathrm{C}$ for SE carried out at $120^{\circ} \mathrm{C}$ and $180^{\circ} \mathrm{C}$. The solid fibres for both $\mathrm{DE}$ and SE carried out at $200^{\circ} \mathrm{C}$ were also filtered and dried to constant mass at $65^{\circ} \mathrm{C}$, and then set aside for further analysis. The remaining solutions for each of the treatment were dried at $65^{\circ} \mathrm{C}$ in the drying cabinet and weighed after cooling in a desiccator to calculate the biomass solubilisation. The percentage of biomass solubilisation was calculated using Equation 1,

$$
\% \text { of biomass solubilisation }=\frac{m_{d}}{m_{i}} \times 100
$$

where $m_{d}$ is the weight of dried solution $(\mathrm{g})$ and $m_{i}$ is the initial weight of biomass (g).

\subsection{Lignin precipitation}

The lignin precipitation method was adapted from Roque (Roque, 2013). The filtrate from delignification process was placed in a freezer at $-20^{\circ} \mathrm{C}$ for 2 hours. After which the ethanol concentration was adjusted to $25 \%$ by adding distilled water. The lignin was recovered using a J2-21 centrifuge (Beckman, Indianapolis, IN, USA) with a JA- 10 rotor at $4^{\circ} \mathrm{C}$ and at 10000 revolutions per minute (rpm) with 17700 relative centrifugal force (RCF) for 10 minutes. The remaining supernatant was dried at $65^{\circ} \mathrm{C}$ for further Klason lignin assay and Fourier Transform Infrared (FTIR) analysis. The resulting precipitated 
lignin was air-dried and stored in $2 \mathrm{~mL}$ Eppendorf tubes at room temperature and later analysed by a Klason lignin assay and FTIR analysis.

\subsection{Klason lignin determination}

The $M x G$ fibre, precipitated lignin, and dried supernatant were analysed for lignin content using the Klason lignin assay (Sluiter et al., 2012). The amount of precipitated lignin was compared to the total amount of lignin in the initial soluble fraction (precipitated lignin and dried supernatant) giving the percentage of lignin recovery using Equation 2,

$$
\% \text { of lignin recovery }=\frac{m_{l}}{m_{l}+m_{s}} \times 100 \%
$$

where $m_{l}$ is the amount of precipitated lignin (g) and $m_{s}$ is the amount of lignin derived from dried supernatant (g).

The starting material for DE was the raw $M x G$ without any pretreatment, and the starting material of SE was the $M x G$ that underwent pretreatment of increasing severity prior to delignification. The percentage of delignification was calculated by comparing the lignin in the insoluble fraction to the lignin present in the starting material using Equation 3,

$$
\% \text { of delignification }=\frac{\text { lignin }_{i}-\text { lignin }_{f}}{\operatorname{lignin}_{i}} \times 100 \%
$$

where $\operatorname{lignin}_{i}$ and $\operatorname{lignin}_{f}$ are the amount of lignin (g) calculated by multiplying the starting biomass used for delignification and the final solid fibres after delignification (g), respectively, with the percentage of Klason lignin.

\subsection{FTIR analysis}

The FTIR analysis was carried out on the samples without any special pretreatment. The IR spectra were determined using a spectrometer (FTIR-6300, JASCO, Easton, MD, USA) over a wavenumber range from $4000 \mathrm{~cm}^{-1}$ to $600 \mathrm{~cm}^{-1}$. The resolution was $4 \mathrm{~cm}^{-1}$ and 32 scans were averaged. Precipitated lignin, dried supernatant, and $M x G$ fibre before and after delignification from both DE and SE were analysed for their differential chemical structures. Principle Component Analysis (PCA) was performed using the Unscrambler ${ }^{\mathrm{TM}}$ Version 10.3 software (CAMO). Two different pre-processing methods (firstly smoothing then normalisation) were performed on each of the three repeated spectrum measurements in the regions of 4000 to $600 \mathrm{~cm}^{-1}$. Analysis of FTIR spectra datasets by PCA for soild fractions $(M x G$ fibre as starting material before and after delignification) and liquid fractions (precipitated lignin and supernatant) determines the differences between spectra in terms of chemical structure and composition of the samples (Durak and Depciuch, 2020).

\subsection{Statistical analysis}

A SPSS software (Version 22, IBM, Armonk, NY, USA) was used for statistical analysis. A one-way analysis of the variance was carried out at $\alpha=0.05$ to compare the different processing routes on the lignin extraction.

\section{Results and Discussion}

\subsection{Percentage of klason lignin for starting material prior delignification}

The percentage of Klason lignin was calculated for $M x G$ fibres in the raw state, for materials after pre-treatment at $120^{\circ} \mathrm{C}$, and for materials after pre-treatment at $180^{\circ} \mathrm{C}$, as shown in Figure 1. The $M x G$ fibres in the raw state was used directly as the starting material for delignification of DE. For SE, the Klason lignin substantially increased after the first temperature step from $120^{\circ} \mathrm{C}$ and $180^{\circ} \mathrm{C}$, from $28.1 \%$ and $32.5 \%$. A difference in the percentage of Klason lignin in the starting materials prior to delignification was observed due to composition differences. Such purity could have been a result of water-soluble hemicellulose removal prior to delignification. Thus, the percentage of Klason lignin in the starting materials prior to delignification was higher for SE than DE $(32.5 \%$ and $27.9 \%$, respectively).

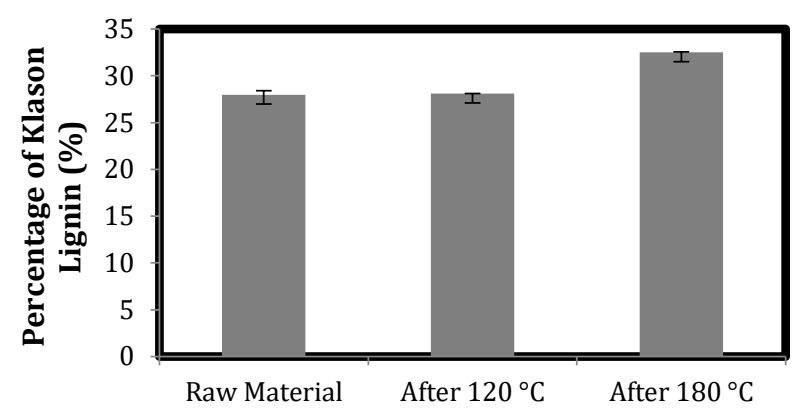

MxG Fibre For Every Step (-)

Figure 1. Percentage of Klason lignin for raw material and $M x G$ fibre for every step prior to delignification

Overall, the SE process of increasing severity resulted in an increase in the concentration of lignin or more purified lignin after each respective stage prior to delignification due to nonstructural components such as pectins, starch, glucose, fructose, lipids and hemicellulose, being removed before the delignification step $\left(200^{\circ} \mathrm{C}\right)$. Hemicellulose is definitely solubilised and removed at $180^{\circ} \mathrm{C}$ resulting in lignin and cellulose-enriched fibres used for delignification of SE processing routes (Pielhop et al., 2015). Compared with DE processing routes, the starting materials contain less purity of lignin since the fibres consist of other components of lignocellulosic biomass including hemicellulose and extractives. Therefore, using $M x G$ fibre as a feedstock that is mostly free from extractives and hemicellulose prior to delignification enables pure lignin to be extracted leaving a cellulose-enriched fibre.

\subsection{Impact of different extraction methods on percentage of biomass solubilisation}

The impact of the different extraction methods was investigated by noting the relative percentage of biomass solubilisation. The results, shown in Figure 2, showed that the percentage of solubilisation from SE $(45.6 \%)$ was higher than for DE (35.6\%). The percentage of biomass solubilisation differed significantly between processes $(p<0.05)$. Overall statistical analysis results were tabulated in Table 1.

The total percentage of solubilisation for SE was calculated by adding the proportion of material post solubilisation after each step of the extraction at $120^{\circ} \mathrm{C}(4.3 \%)$, at $180^{\circ} \mathrm{C}(18.9 \%)$ and at $200^{\circ} \mathrm{C}(22.4 \%)$. The increase in solubilisation with temperature also suggested that more specific lignocellulosic biomass components could be removed or degraded from the liquid fraction at each step of hydrolysis. Figure 2 showed that the percentage of solubilisation increased as the temperature of solution increased. This was due to the unique properties of SCW which is related to polarity of water. Polarity of water is directly dependent upon the temperature (Alghoul et al., 2017); when the temperature of water increased, the polarity of water decreased, thus promotes dissolution of previously insoluble compounds (Galamba et al., 2019). In high-temperature water 
H-bonding weakens, the degree of autoionisation of water increases, thus hydronium ions are generated which act as weak acid or catalysts in SCW processes. These ions break down intermolecular and intramolecular bonds between cellulose, hemicellulose and lignin in the biomass structure (Yang et al., 2017).

Ligero et al. (2011) observed the effects of time and temperature upon the percentage of solubilisation for $M x G$, by direct extraction autohydrolysis. Results ranged from 31 to $37 \%$ at $200^{\circ} \mathrm{C}$ for times from 5 minutes to 60 minutes which is similar to the work for DE presented here. They also agreed that at higher temperatures, more degradation products form in the process liquor with maximum solubilisation at $200^{\circ} \mathrm{C}$ rather than at around $120^{\circ} \mathrm{C}$ and $180^{\circ} \mathrm{C}$ for SE. As can be seen from Figure 2, $4.3 \%$ solubilisation was observed at $120^{\circ} \mathrm{C}$; at this temperature the liquid fraction contains primarily biomass extractives.

In summary, the different processing routes performed in the work affected the solubilisation of targeted components. Organosolv delignification process aims to solubilise lignin and hemicellulose into the aqueous phase and leaving the celluloserich fibre as solid (Cybulska et al., 2017). If DE delignification was chosen as method to recover lignin and hemicellulose from cellulose fibre, separation of hemicellulose from the aqueous phase that also contains lignin and other extractives become more onerous even though lignin can be recovered from the aqueous phase by centrifugation. Thus, the proposed method of SE with increasing severity could improve the extraction of hemicellulose, lignin and cellulose in a biorefinery.

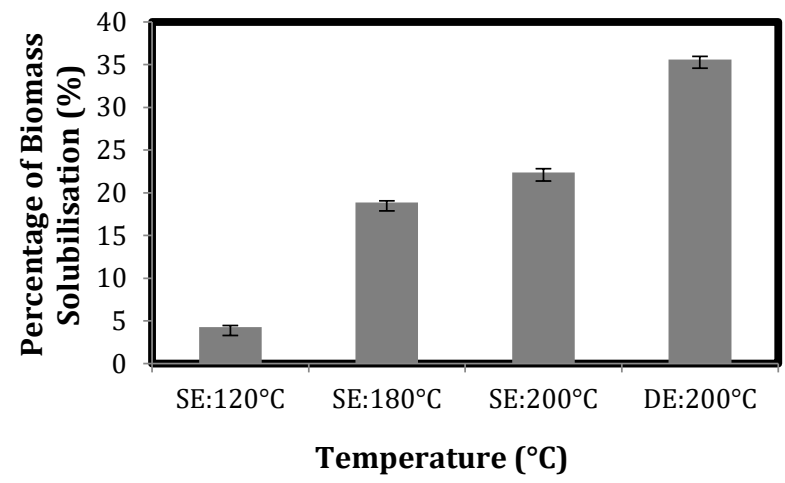

Figure 2. Percentage of biomass solubilisation for SE and DE

\subsection{Impact of different extraction methods on percentage of delignification and lignin recovery}

The lignin content in the insoluble fraction was compared to the amount of lignin in the starting material giving the percentage of delignification. According to Figure 3, the percentage of delignification for SE (58.0\%) was lower than DE $(81.5 \%)$ at which point the percentage of delignification differed significantly $(p<0.05)$.

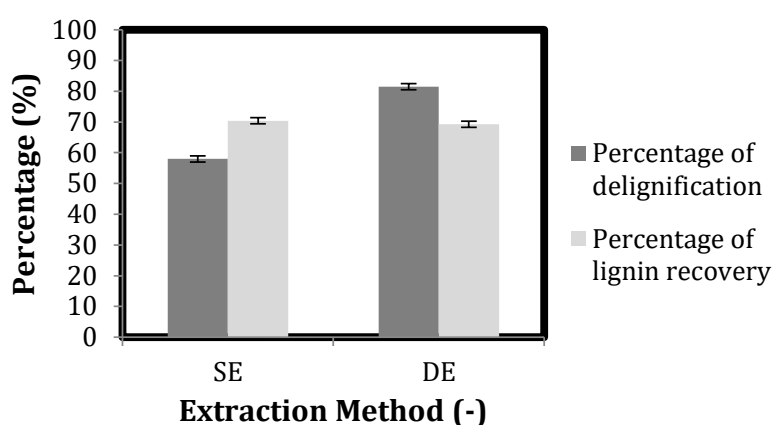

Figure 3. Percentage of delignification and lignin recovery for SE and DE

Table 2 shows the mass balance of lignin for the SE and DE processes that further explain the delignification percentage and lignin recovery. The mass of extracted lignin was almost similar for both DE and SE processing routes even though the delignification was more efficient in the DE processing route in terms of percentage. Similarly, a cellulose purification study within the research group also reported that the delignification was more efficient in the DE route (73\%) than SE (62\%), but the mass of extracted lignin during delignification was similar for both DE and SE routes (Barros, 2016).

The first step of the SE process was performed at a low severity to remove extractives, whilst hemicelluloses were hydrolysed in the second step at a higher severity. The autohydrolysis prior to delignification enabled solubilisation of the hemicellulose and the cleavage of lignin-carbohydrate bonds. However, the efficiency of a subsequent delignification process could be affected (Hage et al., 2010). In a study conducted within research group using the similar extraction method (SE), it was shown that a substantial decrease of hemicellulose from $20.6 \%$ dry weight to $8.8 \%$ dry weight from $120^{\circ} \mathrm{C}$ and $180^{\circ} \mathrm{C}$, respectively. The resultant fibres of delignification for SE showed decrement of hemicellulose $(4.8 \%$ dry weight) in comparison to DE (7.2\% dry weight) (Muniz et al., 2018). Removal of extractives and hemicellulose increased the mean pore size of the substrate, accessibility and improved the enzymatic digestibility of cellulose hydrolysis (Myat and Ryu, 2016).

Table 1. Analysis of variance of SE and DE

\begin{tabular}{|c|c|c|c|c|c|c|}
\hline & & Sum of Squares & $\mathrm{df}$ & Mean Square & $\mathrm{F}$ & Sig. \\
\hline \multirow[t]{3}{*}{ Purity of lignin derived supernatant } & Between Groups & 138.817 & 1 & 138.817 & 107.581 & .000 \\
\hline & Within Groups & 5.161 & 4 & 1.290 & & \\
\hline & Total & 143.978 & 5 & & & \\
\hline \multirow[t]{3}{*}{ Purity of precipitated lignin } & Between Groups & 14.045 & 1 & 14.045 & 264.508 & .000 \\
\hline & Within Groups & .212 & 4 & .053 & & \\
\hline & Total & 14.258 & 5 & & & \\
\hline \multirow[t]{3}{*}{ Percentage of delignification } & Between Groups & 827.905 & 1 & 827.905 & 3741.662 & .000 \\
\hline & Within Groups & .885 & 4 & .221 & & \\
\hline & Total & 828.790 & 5 & & & \\
\hline \multirow[t]{3}{*}{ Percentage of lignin recovery } & Between Groups & 1.540 & 1 & 1.540 & .956 & .383 \\
\hline & Within Groups & 6.442 & 4 & 1.610 & & \\
\hline & Total & 7.982 & 5 & & & \\
\hline \multirow[t]{3}{*}{ Percentage of biomass solubilisation } & Between Groups & 142.984 & 1 & 142.984 & 229.669 & .000 \\
\hline & Within Groups & 2.490 & 4 & .623 & & \\
\hline & Total & 145.474 & 5 & & & \\
\hline
\end{tabular}


Table 2. Mass Balance of Lignin for SE and DE

\begin{tabular}{llll}
\hline Extraction Method & Initial Lignin in Starting Material $(\mathrm{g})$ & Residual Lignin in Cellulose Fibres $(\mathrm{g})$ & Extracted Lignin $(\mathrm{g})$ \\
\hline $\mathrm{DE}$ & $1.32 \pm 0.01$ & $0.24 \pm 0.02$ & $1.08 \pm 0.01$ \\
$\mathrm{SE}$ & $1.57 \pm 0.01$ & $0.66 \pm 0.02$ & $0.91 \pm 0.02$ \\
\hline
\end{tabular}

Because of autohydrolysis, the maximum extractability of the lignin was only achieved in a narrow range of reaction severity after the severe conditions of a long reaction time and high temperature, which consequently decreased the lignin reactivity, solubility, and overall delignification rate (Lehto et al., 2016). The lower delignification percentage for SE may also be caused by the repolymerisation of polysaccharides degradation products, such as furfural from hemicellulose formed during an increased severe pretreatment (Galbe and Wallberg, 2019). In addition, the polymerisation of the carbohydrate and lignin degradation products formed a lignin-like material, termed pseudo-lignin, particularly under high severity pretreatment conditions. The formation of pseudo-lignin can artificially raise the Klason lignin content of pretreated biomass materials and alter the calculation for the delignification percentage (Shinde et al., 2018).

Table 2 shows clear evidence that high residual lignin remained in the cellulose fibres during SE versus DE processing routes. This suggested that higher residual lignin remained associated with the cellulose fibres after an attempted delignification. High residual lignin with cellulose fibres after the SE delignification process could be associated with a covalent bond between the lignin and cellulose that made the lignin strongly absorb to available carbohydrates during the delignification process (Panda, 2016).

An alternative hypothesis of high residual lignin with cellulose fibres after SE also describes that the lignin encounters extensive condensation or re-polymerisation during delignification and causes it to become intractable and unreactive (Glasser, 2019; Rinaldi et al., 2016). Autohydrolysis degrades hemicellulose and part of lignin. The acetal groups in biomass will be released as acetic acid and further catalyze the hydrolysis of hemicellulose and acidolysis of lignin along with lignin condensation. In addition, the lignin condensation reactions could result in an increased molecular weight of lignin that is insoluble in water-ethanol mixtures (Gillet et al., 2017). Thus, the amount of lignin extracted would be decreased because of being trapped within the cellulose fibres.

The lignin recovery percentage for SE and DE was $70.3 \%$ and $69.3 \%$, which were not significantly different with a $95 \%$ confidence level $(p=0.4)$. Lignin recovery via the centrifugation method resulted in two fractions, precipitation after dilution with water and the lignin remaining in the filtrate. Colloidal suspensions in the filtrate emerged but were hard to remove (Yasarla and Ramarao, 2013). Thus, another promising method has been suggested to improve the efficiency of lignin recovery including dissolved air flotation (Macfarlane et al., 2009). While the effects of different methods did not have a notable impact on the lignin recovery percentage, the difference in the lignin's purity was examined.

\subsection{Impact of different extraction methods of lignin purity percentage}

As stated in the above, the soluble lignin fraction was fractionated according to its solubility in ethanol under centrifugation, thereby generating two fractions, a precipitated fraction and supernatant fraction. The precipitated lignin and dried supernatant were analysed by Klason lignin assay to reveal the proportional of lignin in each part. Both precipitated lignin and lignin derived from the dried supernatant from SE (91.5\% and $23.7 \%$, respectively) exhibited a significantly higher purity of lignin $(\mathrm{p}<0.05)$ than from DE which gave $88.4 \%$ and $14.1 \%$, respectively as presented in Figure 4.

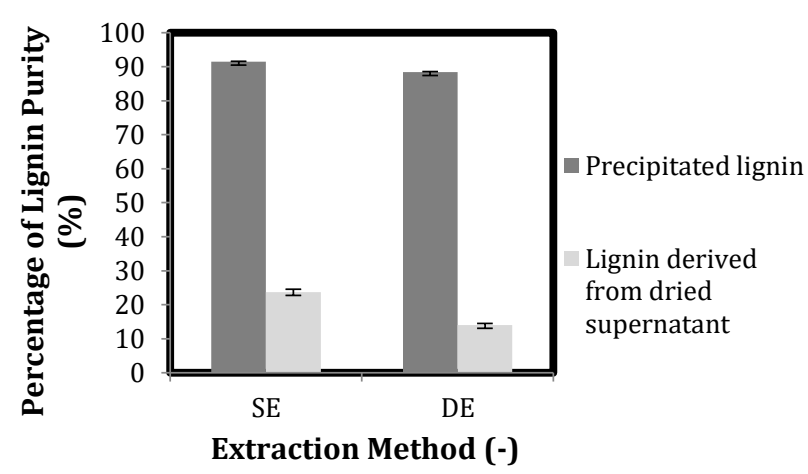

Figure 4. Percentage of lignin purity for SE and DE

Organosolv lignin delivers high purity, low molecular weight, sulfur free products (Zhang et al., 2020) and several studies have proved the high purity of lignin of various biomass obtained using the organosolv method. For instance, a study of lignin recovery from spent liquors from ethanol-water fractionation of sugar cane bagasse achieved a lignin purity of 94\% (Fernando, 2010). Similarly, lignin recovered from wheat straw either using acetic and formic acid based organosolv or an ethanol based organosolv method produced 91\% and 95\% purity lignin, respectively (Wild et al., 2015).

In this study, lignin derived from dried supernatant of SE exhibited higher purity than DE. Thus, it is possible to examine and optimise the operating conditions of the lignin precipitation process to recover more lignin from the process. Lignin removal relies not only on cleavage of ether bonds in lignin macromolecules but also on the capacity of aqueous ethanol solution to dissolve lignin fragments in the solution (Xu et al., 2007). Few factors including solvent concentration, temperature, $\mathrm{pH}$ and turbidity affect lignin precipitation process. For instance, in ethanol pulping of pulp fibres, when ethanol concentration is reduced, lignin precipitation occurs. This is ascribed to ethanol evaporation or dilution of ethanol concentration spent liquor in washing process (Xu et al., 2007). In experimental work carried out on lignin recovery from spent liquors from ethanol-water fractionation of sugarcane bagasse, it was also found that temperature also affected the lignin precipitation process. As the temperature increased, the precipitation and recovered lignin yields decreased (Fernando, 2010).

\subsection{FTIR analysis}

\subsubsection{Solid fraction}

The score plot for the dataset as functions of the two principal components, PC1 (94\% variance) versus PC3 $(2 \%$ variance) is shown in Figure 5 (a). Two distinct clusters are observed. On the left hand side were the spectra for $M x G$ fibre as starting material before delignification and $M x G$ fibre after delignification for $M x G$ which had been subjected to SE. A second cluster on the right hand side, consists of the spectra for $M x G$ fibre before and after delignification for DE.

Thereby, Figure 5 shows the spectra of DE and SE were distinguishable from each other. When comparison is made between samples among SE itself, (SE_FB1 and SE_FB2) and (SE_FA1 and SE_FA3) correlations were in the same quadrant. For DE, (DE_FB1 and DE_FB2) and (DE_FA1 and DE_FA3) 
correlations were in the same quadrant too. The closer the spectra are in the same quadrant; the spectra possess similar chemical composition. Thus, only a spectra was chosen from spectra that have similar chemical composition to be analysed for FTIR analysis.

\subsubsection{Spectra of $M x G$ fibre as starting material before delignification}

The details of reflectance wavenumbers and interpretations of FTIR analysis are outlined in Table 3. The spectra for the materials obtained from DE had a stronger intensity than from SE, as illustrated in Figure 5 (b). The $M x G$ fibres used for DE were from materials that did not undergo any pretreatments, whereas the $M x G$ for $\mathrm{SE}$ used materials that underwent pretreatments at $120^{\circ} \mathrm{C}$ and $180^{\circ} \mathrm{C}$. Both materials showed the characteristic lignin, cellulose, or hemicellulose bands.

In comparison with the spectra of the SE fibre, the spectra of DE fibre had noticeable peaks at $2938 \mathrm{~cm}^{-1}, 2850 \mathrm{~cm}^{-1}, 1650$ $\mathrm{cm}^{-1}$, and $897 \mathrm{~cm}^{-1}$. The peaks at $2938 \mathrm{~cm}^{-1}$ and $2850 \mathrm{~cm}^{-1}$ from the DE materials indicated $\mathrm{CH}$ stretching in aliphatic methylene groups that may have also originated from fatty acids present in the lignin preparations. This is because the $M x G$ fibre used for DE contained extractives that included fatty acids, while the $M x G$ fibre used for SE had these removed during the first step of the SE process $\left(120^{\circ} \mathrm{C}\right)$. There were carbonyl moieties unconjugated $\mathrm{C}=\mathrm{O}$ in xylans (hemicellulose) at $1650 \mathrm{~cm}^{-1}$ for the DE materials. In addition, the spectra of $897 \mathrm{~cm}^{-1}$ of DE had high hemicellulose linkage intensity related to the hemicellulose linkages. This showed that the $M x G$ fibre used in DE was contaminated with large amounts of hemicellulose. According to Figure 5 (b), the intensity of the lignin peak at $1033 \mathrm{~cm}^{-1}$ (G-type aromatic C-H) was strongly enhanced in DE compared to the SE. Nevertheless, these qualitative findings need to be interpreted with caution due to the distortion, aberration or any pretreatment methods in FTIR analysis (Coates, 2000).

\subsubsection{Spectra of MxG fibre after delignification}

The spectra of the $M x G$ fibre or cellulose after delignification was analysed and the following typical cellulose peaks were identified: 3400, 2938, 2850, 1650, 1430, 1375, 1318, 1201, 1163, 1110, 1033, 1059, 897 and $670 \mathrm{~cm}^{-1}$ (Pandey, 1999). As shown in Figure 5 (c), comparisons were made between cellulose fibres of DE showed that the spectra of cellulose fibres of DE were sharper than for SE at $1059 \mathrm{~cm}^{-1}, 1033 \mathrm{~cm}^{-1}$, and $1110 \mathrm{~cm}^{-1}$. The percentage of Klason lignin for cellulose fibres in SE (Section 3.3) revealed that there was more residual lignin remaining in the cellulose fibres that made the cellulose fibres less pure in terms of cellulose characteristics.

The deposited lignin in the cellulose fibres could have a negative impact on the enzymatic cellulose fermentation for subsequent bioethanol production (Luo et al., 2020). The most important peak at $897 \mathrm{~cm}^{-1}$ showed the amorphous type cellulose concentration in SE increased, and further hydrolysis of the cellulose to glucose by enzymatic hydrolysis was efficient compared to crystalline cellulose. A lower value of cellulose crystallinity index resulted in a higher sugar yield and faster hydrolysis rate (Gunny et al., 2017).

Nevertheless, the effect of lignin recovery and crystallinity index towards glucose production for subsequent enzymatic deconstruction were very complicated and difficult to understand as it remains unclear at what conditions the glucose production would prevail depending on various factors such as processing parameters, chemical bonding and materials itself. $\mathrm{Pu}$ et al. (2013) suggested that moderate lignin removal by organosolv pretreatment and retaining few lignin will necessitate the cell wall structure of biomass with least disruption of polysaccharides, further improved cellulose enzymatic digestibility.

Several lines of evidence established that lignin removal was not significantly affected the enzymatic hydrolysis process. In the study of the cell wall changes of Populus biomass in hydrothermally-pretreated biomass of different times at $180^{\circ} \mathrm{C}$, DeMartini et al. (2011) reported that glucose yield via enzymatic hydrolysis enhanced even though lignin removal during hydrothermal process was minimal. In another finding within same group assessing SCW for cellulose hydrolysis and glucose production from $M x G$ via DE and SE approach, although the crystallinity index of cellulose fibres after delignification for SE was higher than DE, the results demonstrated that SE fibres generated higher glucose production than DE. Thus the cellulose fibres were more accessible for fermentative ethanol production (Barros, 2016). It is therefore likely that such lignin content per se in the cellulose fibres did not influence biomass recalcitrance, instead the integration of lignin and polysaccharides within the cell wall, and their associations with one another and with other wall components lead a major contribution (DeMartini et al., 2011; Pattathil et al., 2015).

The peaks at 2938 and $2850 \mathrm{~cm}^{-1}$ clearly broader in DE rather than $\mathrm{SE}$ which the peaks referred to $\mathrm{CH}$ stretching in aliphatic methylene group that can originate from fatty acids present in the lignin preparations. The broad peak of DE may due to that the cellulose fibres of DE contain higher proportion of extractives such as sucrose, fructose, pectins and fatty acids compared to SE which the extractives were removed at previous step prior to delignification process.

\subsubsection{Liquid fraction}

The score plot of PC2 (variability; 13\%) x PC1 (variability, $85 \%$ ) is shown in Figure 6 (a). There are two definite clusters in the PCA data. On the left hand side were the spectra for lignin and supernatant of SE. A second cluster on the right hand side, consists of spectra of lignin and supernatant for DE. These findings suggested that in general, the impact of operating parameters upon lignin and supernatant were different between SE and DE.

Scores of respective samples of DE and SE were close within each other in the same quadrant. The same scores illustrated that the spectra possess similar chemical composition. When comparison is made between samples among SE itself, (SE_L2 and SE_L3) and (SE_S1 and SE_S2) correlations were in the same quadrant. For DE, (DE_L1 and DE_L2) and (DE_S1, DE_S2 and DE_S3) correlations were in the same quadrant too. In general, the score plot can differentiate the samples according to different extraction methods and to answer simple questions such as if the spectra represent significant differences.

The spectra of precipitated lignin, analysed by FTIR for both DE and SE are shown in Figure 6 (b). In general, the spectra of precipitated lignin for SE had stronger and broader intensity spectra than DE. The typical peaks at wavenumbers attributed to lignin were found at $3400,1705,1600,1650,1515,1460$, $1425,1326,1265,1220,1033,1118,915$, and $833 \mathrm{~cm}^{-1}$. Both lignin from different processing routes showed peaks at 2938 $\mathrm{cm}^{-1}$ and $2850 \mathrm{~cm}^{-1}$ which correspond to $\mathrm{C}-\mathrm{H}$ stretching in aromatic methoxyl groups and in methyl and methylene groups of side chains (Boeriu et al., 2004). An asymmetry and broadening of the spectra at $1705 \mathrm{~cm}^{-1}$ and $1600 \mathrm{~cm}^{-1}$, respectively appeared for both lignin. This most likely resulted from weak absorptions around $1650 \mathrm{~cm}^{-1}$ due to protein impurity and water associated with the lignin (Boeriu et al., 2004).

The major finding of precipitated lignin at different processing routes is the lignin of SE showed a wider intensity band at $3400 \mathrm{~cm}^{-1}$ than $\mathrm{DE}$, which indicated the presence of $\mathrm{OH}$ stretching vibrations in aromatic and aliphatic $\mathrm{OH}$ groups (Alriols et al., 2010; Boeriu et al., 2004). The wider intensity of 


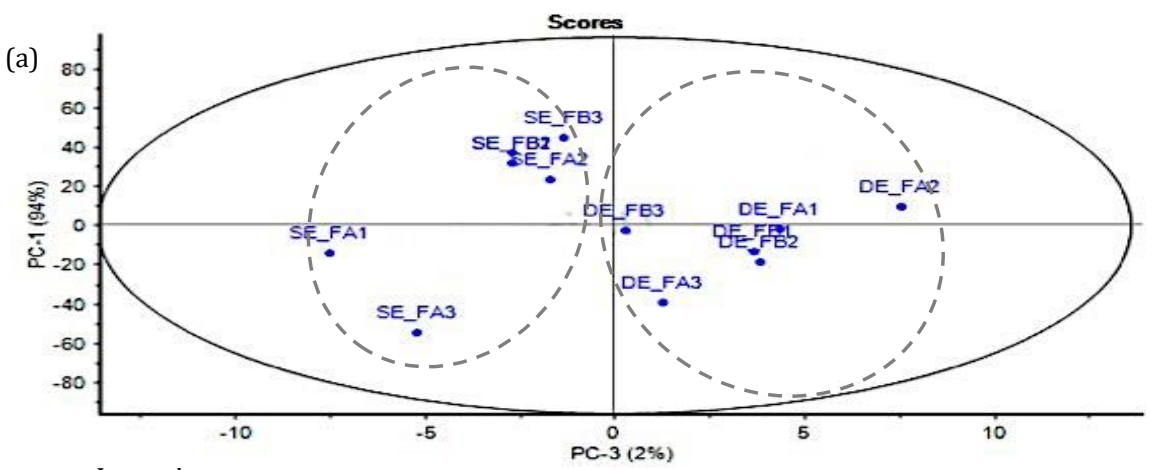

Legend:

SE_FA: Sequential extraction- $M x G$ fibre after delignification

SE_FB: Sequential extraction- $M x G$ fibre before delignificatio

DE_FA: Direct extraction- $M x G$ fibre after delignification

DE_FB: Direct extraction- $M x G$ fibre before delignification

**1,2,3- Repetition of spectra
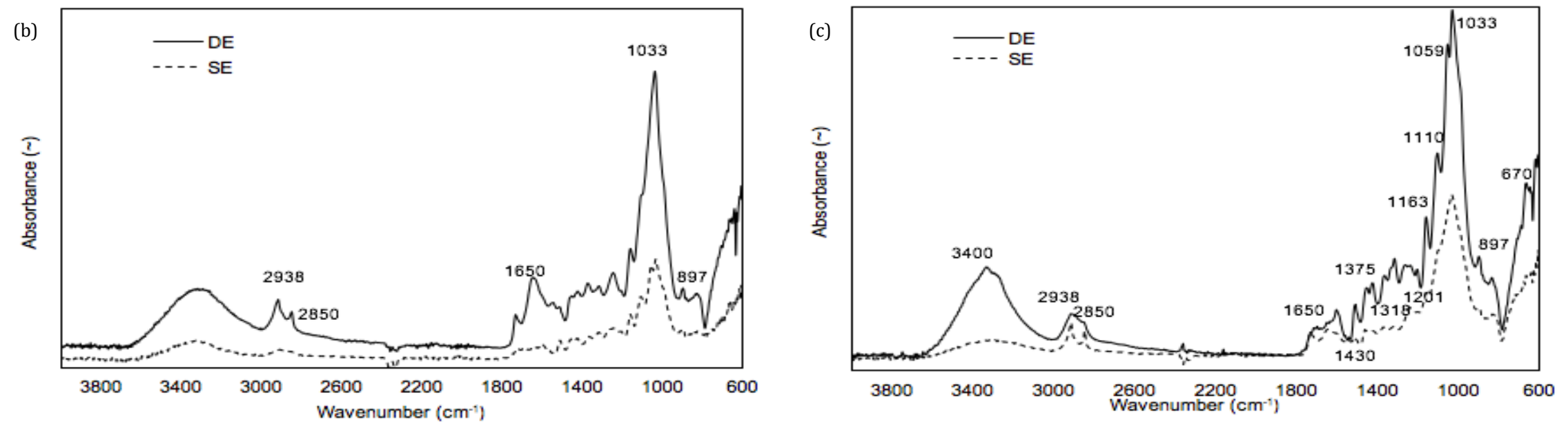

Figure 5. PCA and FTIR analysis on solid fraction (a) PCA scores plot (b) $M x G$ fibre as starting material before delignification (c) $M x G$ fibre after delignification of DE and SE 
Table 3. Wavenumbers and Interpretations

\begin{tabular}{|c|c|c|c|c|c|}
\hline Wavenumber $\left(\mathrm{cm}^{-1}\right)$ & Interpretation & References & Wavenumber $\left(\mathrm{cm}^{-1}\right)$ & Interpretation & References \\
\hline 3400 & $\begin{array}{l}\text { Aromatic and aliphatic hydroxyl } \\
\text { groups }\end{array}$ & (Boeriu et al., 2004) & 1201 & OH deformation & (Boeriu et al., 2004; Pandey, 1999) \\
\hline 2938,2850 & $\begin{array}{l}\mathrm{CH} \text { stretching in aromatic } \\
\text { methoxyl groups and in methyl } \\
\text { and methylene groups of side } \\
\text { chains }\end{array}$ & $\begin{array}{l}\text { (Szczepkowski et al., } \\
\text { 2007) }\end{array}$ & 1163 & COC asymmetric vibration & (Boeriu et al., 2004; Pandey, 1999) \\
\hline 1705 & $\begin{array}{l}\text { Weak to medium bands } \\
\text { originating from unconjugated } \\
\text { carbonyl/carboxyl stretching. } \\
\text { Ester carbonyl vibration in } \\
\text { acetyl, feryloyl, p-coumaryl, } \\
\text { groups in lignin and } \\
\text { hemicelluloses }\end{array}$ & $\begin{array}{l}\text { (Boeriu et al., 2004; } \\
\text { Pandey, 1999) }\end{array}$ & 1118 & $\begin{array}{l}\text { Syringyl (S)-type aromatic C-H in- } \\
\text { plane deformations }\end{array}$ & (Alriols et al., 2010) \\
\hline 1650 & $\begin{array}{l}\mathrm{OH} \text { bending with adsorbed } \\
\text { water, Carbonyl moieties } \\
\text { (unconjugated } \mathrm{C}=\mathrm{O} \text { in xylans } \\
\text { (hemicellulose). }\end{array}$ & $\begin{array}{l}\text { (Boeriu et al., 2004; } \\
\text { Pandey, 1999) }\end{array}$ & 1110 & Glucose ring stretch & (Pandey, 1999) \\
\hline $1600,1515,1425$ & $\begin{array}{l}\text { Aromatic phenylpropane } \\
\text { skeleton vibrations }\end{array}$ & (Boeriu et al., 2004) & 1059 & C-O stretching & (Boeriu et al., 2004; Pandey, 1999) \\
\hline 1460 & $\mathrm{C}-\mathrm{H}$ aliphatic bonds & (Boeriu et al., 2004) & 1033,915 & $\begin{array}{l}\text { G-type aromatic C-H in-plane and } \\
\text { out of the plane bending at } 1033 \\
\mathrm{~cm}^{-1} \text {, the former and at } 915 \mathrm{~cm}^{-1}\end{array}$ & (Boeriu et al., 2004) \\
\hline 1430 & $\mathrm{C}-\mathrm{H}$ deformation (asymmetric) & $\begin{array}{l}\text { (Alriols et al., 2010; } \\
\text { Boeriu et al., 2004) }\end{array}$ & 897 & $\begin{array}{l}\text { Vibration attributed to } \beta(1 \rightarrow 4) \\
\text { linkage (glucosidic bond between } \\
\text { two glucose units) formation of } \\
\beta(1 \rightarrow 4) \quad \text { glucopyranose } \\
\text { macromolecules (cellulose) and } \\
\text { hemicellulose; increases with the } \\
\text { increase of amorphous cellulose }\end{array}$ & $\begin{array}{l}\text { (Abidi et al., 2008; Boeriu et al., 2004; } \\
\text { Ibrahim et al., 2011) }\end{array}$ \\
\hline 1375 & $\mathrm{C}-\mathrm{H}$ deformation (symmetric) & (Boeriu et al., 2004) & 833 & $\begin{array}{l}\text { S-type aromatic C-H out-of-plane } \\
\text { deformation }\end{array}$ & (Boeriu et al., 2004) \\
\hline 1318 & $\mathrm{CH}_{2}$ wagging & $\begin{array}{l}\text { (Boeriu et al., 2004; } \\
\text { Pandey, 1999) }\end{array}$ & 670 & C-OH-out-of-plane bending mode & (Boeriu et al., 2004) \\
\hline 1326 & $\begin{array}{l}\mathrm{S} \text { ring breathing with } \mathrm{C}-\mathrm{O} \\
\text { stretching } \\
\mathrm{S} \text { ring plus } \mathrm{G} \text { ring condensed } \\
\text { and the vibration at } 833 \mathrm{~cm}^{-1} \text {, } \\
\text { that arise from the } \mathrm{C}-\mathrm{H} \text { out-of- } \\
\text { plane in position } 2 \text { and } 6 \text { of } \mathrm{S} \\
\text { units }\end{array}$ & $\begin{array}{l}\text { (Alriols et al., 2010; } \\
\text { Boeriu et al., 2004) }\end{array}$ & & & \\
\hline 1265 & $\begin{array}{l}\mathrm{G} \text { ring breathing with } \mathrm{C}-\mathrm{O} \\
\text { stretching }\end{array}$ & (Boeriu et al., 2004) & & & \\
\hline 1220 & Ether bridges & (Boeriu et al., 2004) & & & \\
\hline
\end{tabular}


(a)

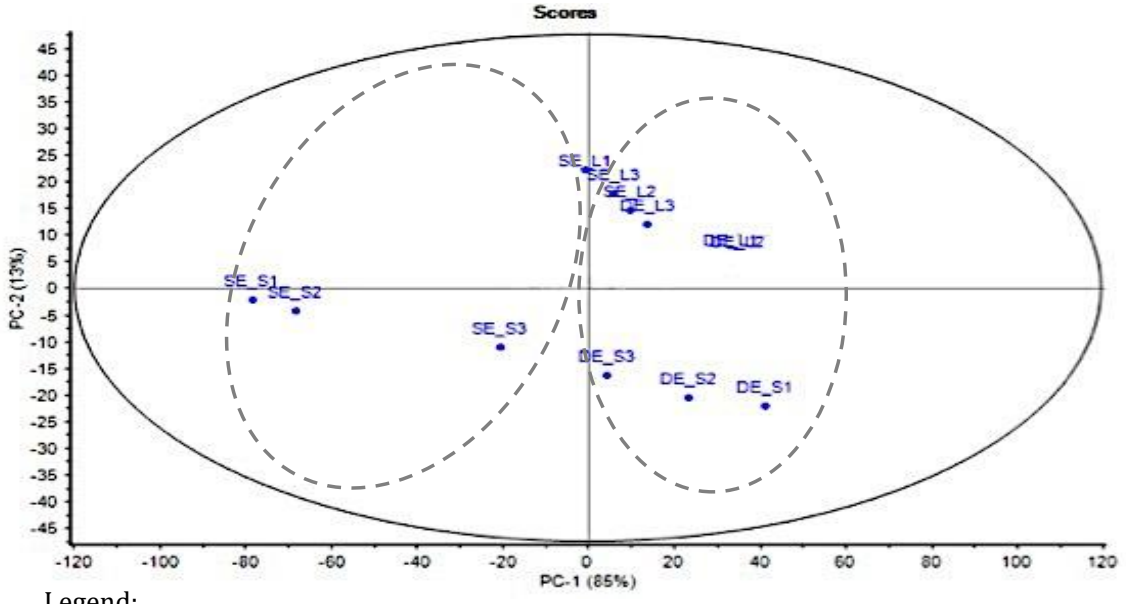

Legend:

SE_L: Sequential extraction- Precipitated lignin

SE_S: Sequential extraction- Supernatant

DE_L: Direct extraction- Precipitated lignin

DE_S: Direct extraction- Supernatant

**1,2,3-repetition of spectra
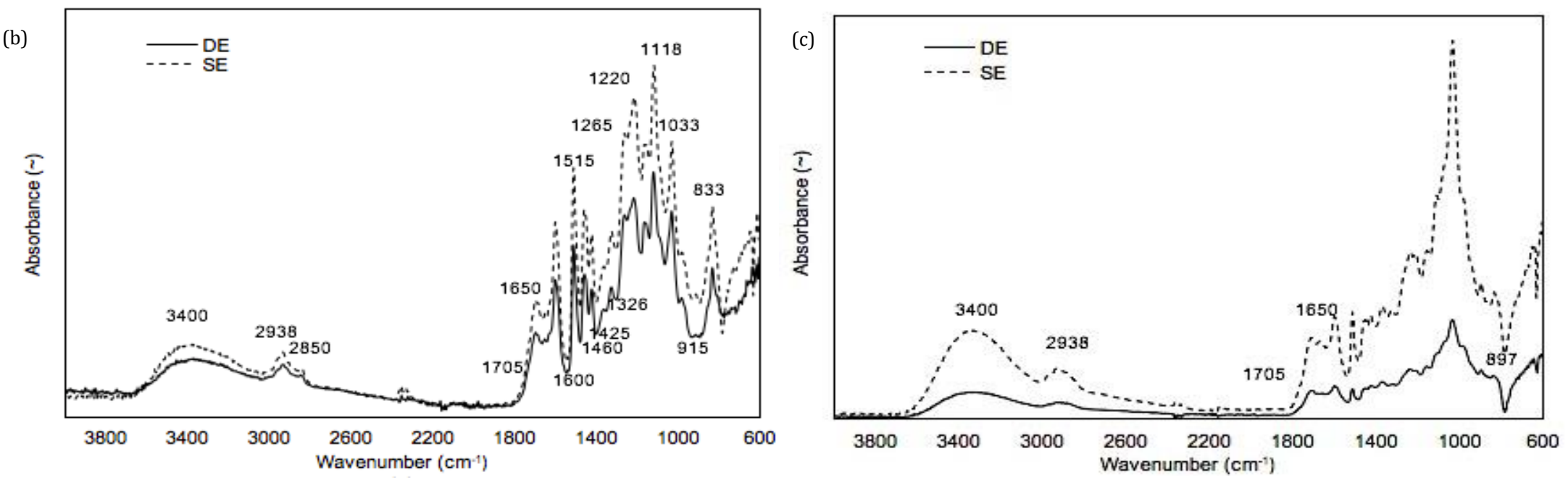

Figure 6. PCA and FTIR analysis on liquid fraction (a) PCA scores plot (b) Precipitated lignin (c) Supernatant of DE and SE 
hydroxyl groups characterisation for lignin of SE was due to the cleavage association of polysaccharides such as starch, hemicellulose and cellulose with lignin during the pretreatment of increasing severity (Cao et al., 2012; Wang et al., 2016). Removal of lignin from polysaccharides is beneficial to recover purified lignin, that exposing more accessible hydroxyl group of lignin derived from SE (Sasaki et al., 2015). The abundance of hydroxyl groups, demonstrating that lignin recovered can be a good alternative to polyols in the production of lignin polymer composites through lignin depolymerisation and modification at higher bio-replacement ratios (Mahmood et al., 2016). However, when the hydroxyl group peak is of interest, strong water absorption (around 3000-4000 $\mathrm{cm}^{-1}$ ) could have influenced the results obtained and in turn, relatively led into misinterpretation of the data. However, the conclusion of the findings should be treated with cautions, as the findings related to the availability of hydroxyl groups can be validated by various methods in future such as size exclusion chromatography and potentiometric titration, respectively.

The wavenumbers of 2938 and $2850 \mathrm{~cm}^{-1}$ are attributed to $\mathrm{C}-\mathrm{H}$ stretching in aromatic methoxyl groups and in methyl and methylene groups of side chains (Boeriu et al., 2004). An asymmetry and broadening of the spectra at 1705 and $1600 \mathrm{~cm}^{-}$ ${ }_{1}^{1}$ probably resulted from weak absorptions around $1650 \mathrm{~cm}^{-1}$ due to protein impurity and water associated with lignin, respectively (Boeriu et al., 2004). The ether bridges at $1220 \mathrm{~cm}^{-}$ 1 are associated with the extraction process; SCW cleaves hemiacetal linkages, thus, liberating acetic acids during biomass treatment, which then facilitates the breakage of ether linkages in biomass (Behera et al., 2014). The generated acetic acids act as a catalyst causing autohydrolysis, the formation and removal of oligosaccharides, and further hydrolyse hemicellulose to monomeric sugars, furfural and hydroxymethylfurfural (Kim, 2018). In addition, spectra which wavenumber apportioned to lignin is strongly enhanced $\left(600 \mathrm{~cm}^{-1}\right.$ to $\left.1700 \mathrm{~cm}^{-1}\right)$ in SE compared with DE, where these peaks are reduced. This could be due to a relative increase in the purity of lignin in the SE as hemicellulose was removed in the previous step in the pretreatment before the delignification process (Mosier et al., 2005).

The FTIR spectra of supernatant from both extraction methods are presented in Figure 6 (c). In comparison to DE and SE, the spectra of supernatant of DE had a weaker intensity than for SE. Most of wavenumbers in the spectra are attributed to lignin, but there are also those which relate to cellulose and hemicellulose characteristics $\left(1705\right.$ to 1720,1650 and $897 \mathrm{~cm}^{-}$ 1). However, the intensity of the peak was low compared to the lignin peak. Strong intensity spectra of dried supernatant for SE may due to more lignin in the dried supernatant. The purity of lignin analysed by Klason lignin assay (Section 3.4) in dried supernatant for SE resulted higher (23.7\%) than DE (14.1\%).

\section{Conclusion}

The SE method offers valuable insight into biomass fractionation to recover high quality streams of each of the biomass major components whereby lignin and hemicelluloses were hydrolysed and could recover from the liquid fraction, leading to a relatively effective fractionation of cellulose-rich solid fibres. In contrast, DE produced a liquid fraction that comprised various components including extractives, lignin, hemicellulose and sugar degradation products and the major challenge is the hemicellulose recovery during separation process while maintaining the lignin structure as well as maximising the lignin recovery. In summary, lignin derived from the SE processing routes demonstrated high lignin purity and suitably hydroxyl groups, making the lignin produced had suitable characteristics for subsequent lignin depolymerisation and modification corresponding to lignin value-added bio-based materials.

\section{Authors contributions}

Muhammad Hazwan Hamzah designed and developed the experimental and the conceptual framework, analyzed the data, and; wrote the manuscript. Steve Bowra and Philip Cox devised, supervised the project and the findings of this work; and verified the analytical methods.

\section{Conflict of interests}

The authors declare that they have no competing interests to disclose that might be perceived as affecting the objectivity of this manuscript.

\section{Acknowledgments}

This study is financially supported by Ministry of Higher Education Malaysia and Universiti Putra Malaysia under 'Skim Latihan IPTA (SLAI)'. The authors would also like to thank Phytatec (U.K.) Ltd. for providing biomass feedstock for this research. We would like to thanks Steve Bowra for his input for this study.

\section{References}

Abidi, N., Hequet, E., Cabrales, L., Gannaway, J., Wilkins, T., \& Wells, L. W. (2008). Evaluating cell wall structure and composition of developing cotton fibers using Fourier transform infrared spectroscopy and thermogravimetric analysis. Journal of Applied Polymer Science, 107(1), 476486.

Alghoul, Z. M., Ogden, P. B., \& Dorsey, J. G. (2017). Characterization of the polarity of subcritical water. Journal of Chromatography A, 1486, 42-49. https://doi.org/10.1016/j.chroma.2016.12.072

Alriols, M. G., García, A., Llano-ponte, R., \& Labidi, J. (2010). Combined organosolv and ultrafiltration lignocellulosic biorefinery process. Chemical Engineering Journal, 157(1), 113-120.

https://doi.org/http://dx.doi.org/10.1016/j.cej.2009.10. 058

Alvira, P., Tomás-Pejó, E., Ballesteros, M., \& Negro, M. J. (2010). Pretreatment technologies for an efficient bioethanol production process based on enzymatic hydrolysis: A review. Bioresource Technology, 101(13), 4851-4861. https://doi.org/10.1016/j.biortech.2009.11.093

Amendola, D., De Faveri, D. M., Egües, I., Serrano, L., Labidi, J., \& Spigno, G. (2012). Autohydrolysis and organosolv process for recovery of hemicelluloses, phenolic compounds and lignin from grape stalks. Bioresource Technology, 107, 267-274 https://doi.org/10.1016/j.biortech.2011.12.108

Attard, T. M., \& Hunt, A. J. (2018). Introduction to High-pressure Solvent Systems. In A. J. Hunt \& T. M. Attard (Eds.), RSC Green Chemistry (pp. 1-13). https://doi.org/10.1039/9781788013543-00001

Barros, A. M. De. (2016). A new approach to develop cost-effective lignocellulosic bioethanol production. University of Birmingham.

Behera, S., Arora, R., Nandhagopal, N., \& Kumar, S. (2014). Importance of chemical pretreatment for bioconversion of lignocellulosic biomass. Renewable and Sustainable Energy Reviews, 36, 91-106. https://doi.org/10.1016/j.rser.2014.04.047

Boeriu, C. G., Bravo, D., Gosselink, R. J. A., \& van Dam, J. E. G. (2004). Characterisation of structure-dependent functional properties of lignin with infrared spectroscopy. 
Industrial Crops and Products, 20(2), 205-218. https://doi.org/10.1016/j.indcrop.2004.04.022

Cao, S., Pu, Y., Studer, M., Wyman, C., Ragauskas, A. J., Ragauskas, A. J., ... Lundquist, K. (2012). Chemical transformations of Populus trichocarpa during dilute acid pretreatment. RSC Advances, 2(29), 10925-10936. https://doi.org/10.1039/c2ra22045h

Coates, J. (2000). Interpretation of Infrared Spectra , A Practical Approach Interpretation of Infrared Spectra , A Practical Approach. In R. A. Meyers (Ed.), Encyclopedia of Analytical Chemistry. Chichester, UK: John \& Wiley Sons, Inc.

Cybulska, I., Brudecki, G. P., Zembrzuska, J., Schmidt, J. E., Lopez, C. G.-B., \& Thomsen, M. H. (2017). Organosolv delignification of agricultural residues (date palm fronds, Phoenix dactylifera L.) of the United Arab Emirates. Applied Energy, 185(2), 1040-1050. https://doi.org/10.1016/j.apenergy.2016.01.094

DeMartini, J. D., Pattathil, S., Avci, U., Szekalski, K., Mazumder, K., Hahn, M. G., \& Wyman, C. E. (2011). Application of monoclonal antibodies to investigate plant cell wall deconstruction for biofuels production. Energy Environ. Sci., 4(10), 4332-4339. https://doi.org/10.1039/C1EE02112E

Durak, T., \& Depciuch, J. (2020). Effect of plant sample preparation and measuring methods on ATR-FTIR spectra results. Environmental and Experimental Botany, 169(August 2019), 103915. https://doi.org/10.1016/j.envexpbot.2019.103915

El Hage, R., Chrusciel, L., Desharnais, L., \& Brosse, N. (2010). Effect of autohydrolysis of Miscanthus $\mathrm{x}$ giganteus on lignin structure and organosolv delignification. Bioresource Technology, 101(23), 9321-9329. https://doi.org/10.1016/j.biortech.2010.06.143

Fernando, E. F. (2010). Lignin recovery from spent liquors from ethanol-water fractionation of sugar cane bagasse. Cellulose Chemistry and Technology, 44(9), 311-318.

Galamba, N., Paiva, A., Barreiros, S., \& Simões, P. (2019). Solubility of polar and nonpolar aromatic molecules in subcritical water: the role of the dielectric constant. Journal of Chemical Theory and Computation, 15(11), 6277-6293. https://doi.org/10.1021/acs.jctc.9b00505

Galbe, M., \& Wallberg, O. (2019). Biotechnology for Biofuels Pretreatment for biorefineries: a review of common methods for efficient utilisation of lignocellulosic materials. Biotechnology for Biofuels, 12(294), 1-26. https://doi.org/10.1186/s13068-019-1634-1

Ganewatta, M. S., Lokupitiya, H. N., \& Tang, C. (2019). Lignin biopolymers in the age of controlled polymerization. Polymers, 11(7), 1-44. https://doi.org/10.3390/polym11071176

Gillet, S., Aguedo, M., Petitjean, L., Morais, A. R. C., Da Costa Lopes, A. M., Łukasik, R. M., \& Anastas, P. T. (2017). Lignin transformations for high value applications: Towards targeted modifications using green chemistry. Green Chemistry, 19(18), 4200-4233. https://doi.org/10.1039/c7gc01479a

Glasser, W. G. (2019). About Making Lignin Great Again-Some Lessons From the Past. Frontiers in Chemistry, 7(August), 1-17. https://doi.org/10.3389/fchem.2019.00565

Gunny, A. A. N., Arbain, D., \& Jamal, P. (2017). Effect of structural changes of lignocelluloses material upon pre-treatment using green solvents. AIP Conference Proceedings, 1835(April), 1-5. https://doi.org/10.1063/1.4981844

Huijgen, W. J. J., Smit, A. T., de Wild, P. J., \& den Uil, H. (2012). Fractionation of wheat straw by prehydrolysis, organosolv delignification and enzymatic hydrolysis for production of sugars and lignin. Bioresource Technology, 114 , 389-398. https://doi.org/10.1016/j.biortech.2012.02.143
Ibrahim, M. M., El-Zawawy, W. K., Abdel-Fattah, Y. R., Soliman, N. A., \& Agblevor, F. A. (2011). Comparison of alkaline pulping with steam explosion for glucose production from rice straw. Carbohydrate Polymers, 83(2), 720-726. https://doi.org/10.1016/j.carbpol.2010.08.046

Kalnins, R. (2017). Production of Preobitic Rich Extracts from Lignocellulosic Biomass using Subcritical Water. University of Birmingham.

Kim, D. (2018). Physico-chemical conversion of lignocellulose: Inhibitor effects and detoxification strategies: A mini review. Molecules, 23(2), 1-21. https://doi.org/10.3390/molecules23020309

Laurichesse, S., \& Avérous, L. (2014). Chemical modification of lignins: Towards biobased polymers. Progress in Polymer Science, 39(7), 1266-1290. https://doi.org/10.1016/j.progpolymsci.2013.11.004

Lehto, J., Alén, R., \& Kleen, M. (2016). Sulfur-free pulping of hotwater-extracted spruce sawdust. Nordic Pulp and Paper Research Journal, 31(1), 41-48. https://doi.org/10.3183/npprj-2016-31-01-p041-048

Li, T., \& Takkellapati, S. (2019). The current and emerging sources of technical lignins and their applications. Biofuels, Bioproducts and Biorefining, 12(5), 756-787. https://doi.org/10.1002/bbb.1913.Submit

Ligero, P., Kolk, J. C. van der, Vega, A. de, \& Dam, J. E. G. van. (2011). Production of xylo-oligosaccharides from Miscanthus x giganteus by autohydrolysis. BioResources, 6(4), 4417-4429.

Luo, X., Gong, Z., Shi, J., Chen, L., Zhu, W., Zhou, Y., ... Liu, J. (2020). Integrating Benzenesulfonic Acid Pretreatment and BioBased Lignin-Shielding Agent for Robust Enzymatic Conversion of Cellulose in Bamboo. Polymers, 12(1), 191. https://doi.org/10.3390/polym12010191

Macfarlane, A. L., Prestidge, R., Farid, M. M., \& Chen, J. J. J. (2009). Dissolved air flotation: A novel approach to recovery of organosolv lignin. Chemical Engineering Journal, 148(1), 15-19. https://doi.org/10.1016/j.cej.2008.07.036

Mahmood, N., Yuan, Z., Schmidt, J., \& Xu, C. (2016). Depolymerisation of lignins and their applications for the preparation of polyols and rigid polyurethane foams: A review. Renewable and Sustainable Energy Reviews, 60, 317-329. https://doi.org/10.1016/j.rser.2016.01.037

Manjare, S. D., \& Dhingra, K. (2019). Supercritical fluids in separation and purification: A review. Materials Science for Energy Technologies, 2(3), 463-484. https://doi.org/10.1016/j.mset.2019.04.005

Matsushita, Y. (2015). Conversion of technical lignins to functional materials with retained polymeric properties. Journal of Wood Science, 61(3), 230-250. https://doi.org/10.1007/s10086-015-1470-2

Morais, A. R. C., Da Costa Lopes, A. M., \& Bogel-Łukasik, R. (2015). Carbon dioxide in biomass processing: Contributions to the green biorefinery concept. Chemical Reviews, 115(1), 3-27. https://doi.org/10.1021/cr500330z

Mosier, N., Wyman, C., Dale, B., Elander, R., Lee, Y. Y., Holtzapple, M., \& Ladisch, M. (2005). Features of promising technologies for pretreatment of lignocellulosic biomass. Bioresource Technology, 96(6), 673-686. https://doi.org/10.1016/j.biortech.2004.06.025

Muniz Kubota, A., Kalnins, R., \& Overton, T. W. (2018). A biorefinery approach for fractionation of Miscanthus lignocellulose using subcritical water extraction and a modified organosolv process. Biomass and Bioenergy, 111, 52-59. https://doi.org/10.1016/j.biombioe.2018.01.019

Myat, L. I. N., \& Ryu, G. (2016). Pretreatments and factors affecting saccharification and fermentation for lignocellulosic ethanol production. Cellulose Chemistry and Technology, 50(2), 177-188.

Ouyang, X., Huang, X., Hendriks, B. M. S., Boot, M. D., \& Hensen, E. 
J. M. (2018). Coupling organosolv fractionation and reductive depolymerization of woody biomass in a twostep catalytic process. Green Chemistry, 20(10), 23082319. https://doi.org/10.1039/c8gc00639c

Panda, H. (2016). Lignin and Hemicellulose. In Handbook on Coal , Lignin , Wood and Rosin Processing (pp. 166-207). Delhi, India: NIIR Project Consultancy Services.

Pandey, K. K. (1999). A study of chemical structure of soft and harwood and wood polymers by FTIR spectrscopy. Journal of Applied Polymer Science, 71(12), 1969-1975.

Pasquini, D., Pimenta, M. T. B., Ferreira, L. H., \& Curvelo, A. A. da S. (2005). Extraction of lignin from sugar cane bagasse and Pinus taeda wood chips using ethanol-water mixtures and carbon dioxide at high pressures. The Journal of Supercritical Fluids, 36(1), 31-39. https://doi.org/10.1016/j.supflu.2005.03.004

Pattathil, S., Avci, U., Zhang, T., Cardenas, C. L., \& Hahn, M. G. (2015). Immunological approaches to biomass characterization and utilization. Frontiers in Bioengineering and Biotechnology, 3, 1-14. https://doi.org/10.3389/fbioe.2015.00173

Pielhop, T., Larrazábal, G. O., Studer, M. H., Brethauer, S., Seidel, C.-M., \& Rudolf von Rohr, P. (2015). Lignin repolymerisation in spruce autohydrolysis pretreatment increases cellulase deactivation. Green Chem., 17(6), 3521-3532. https://doi.org/10.1039/C4GC02381A

$\mathrm{Pu}$, Y., Hu, F., Huang, F., Davison, B. H., \& Ragauskas, A. J. (2013). Assessing the molecular structure basis for biomass recalcitrance during dilute acid and hydrothermal pretreatments. Biotechnology for Biofuels, 6(15), 1-13. https://doi.org/10.1186/1754-6834-6-15

Rinaldi, R., Jastrzebski, R., Clough, M. T., Ralph, J., Kennema, M., Bruijnincx, P. C. A., \& Weckhuysen, B. M. (2016). Paving the way for lignin valorisation: Recent advances in bioengineering, biorefining and catalysis. Angewandte Chemie International Edition, 55(29), 8164-8215. https://doi.org/10.1002/anie.201510351

Roque, R. M. N. (2013). Hydrolysis of lignocellulosic biomass by a modified organosolv Method on a biorefinery perspective example of Miscanthus $x$ giganteus. University of Birmingham.

Roque, R. M. N., Baig, M. N., Leeke, G. A., Bowra, S., \& Santos, R. C. D. (2012). Study on sub-critical water mediated hydrolysis of Miscanthus a lignocellulosic biomass. Resources, Conservation and Recycling, 59, 43-46. https://doi.org/10.1016/j.resconrec.2011.06.007

Sasaki, K., Okamoto, M., Shirai, T., Tsuge, Y., Teramura, H., Sasaki, D., ... Kondo, A. (2015). Precipitate obtained following membrane separation of hydrothermally pretreated rice straw liquid revealed by $2 \mathrm{D}$ NMR to have high lignin content. Biotechnology for Biofuels, 8(88), 1-10. https://doi.org/10.1186/s13068-015-0273-4

Shinde, S. D., Meng, X., Kumar, R., \& Ragauskas, A. J. (2018). Recent advances in understanding the pseudo-lignin formation in a lignocellulosic biorefinery. Green Chemistry, 20(10), 2192-2205. https://doi.org/10.1039/c8gc00353j

Sluiter, A., Hames, B., Ruiz, R., Scarlata, C., Sluiter, J., Templeton, D., \& Crocker, D. (2012). Determination of Structural Carbohydrates and Lignin in Biomass. In Laboratory Analytical Procedure (LAP). https://doi.org/NREL/TP510-42618

Szczepkowski, A., Nicewicz, D., \& Koczon, P. (2007). The relationship between tree health and chemical composition of beech (Fagus sylvatica L.) and oak (Quercus robur L.) wood of polish provenances. Acta Scientiarum Polonorum - Silvarum Colendarum Ratio et Industria Lignaria, 6(3), 77-88.

Ten, E., \& Vermerris, W. (2015). Recent developments in polymers derived from industrial lignin. Journal of Applied Polymer Science, 132(24), 1-13. https://doi.org/10.1002/app.42069

Wang, Z.-W., Zhu, M.-Q., Li, M.-F., Wang, J.-Q., Wei, Q., Sun, R.-C., ... Tschaplinski, T. (2016). Comprehensive evaluation of the liquid fraction during the hydrothermal treatment of rapeseed straw. Biotechnology for Biofuels, 9(142), 1-16. https://doi.org/10.1186/s13068-016-0552-8

Wild, P. J. de, Huijgen, W. J. J., Linden, R. van der, Uil, H. den, Snelders, J., \& Benjelloun-Mlayah, B. (2015). Organosolv fractionation of lignocellulosic biomass for an integrated biorefinery. Netherlands.

Xu, Y., Li, K., \& Zhang, M. (2007). Lignin precipitation on the pulp fibers in the ethanol-based organosolv pulping. Colloids and Surfaces A: Physicochemical and Engineering Aspects, 301(1-3), https://doi.org/10.1016/j.colsurfa.2006.12.078 255-263.

Yang, B., Tao, L., \& Wyman, C. E. (2017). Strengths, challenges, and opportunities for hydrothermal pretreatment in lignocellulosic biorefineries. Biofuels, Bioproducts and Biorefining, 12(1), 125-138. https://doi.org/https://doi.org/10.1002/bbb.1825

Yasarla, L. R., \& Ramarao, B. V. (2013). Lignin removal from lignocellulosic hydrolysates by flocculation with polyethylene oxide. Journal of Biobased Materials and Bioenergy, 7(6), 684-689. https://doi.org/10.1166/jbmb.2013.1398

Zhang, Q., Li, H., Guo, Z., \& Xu, F. (2020). High purity and low molecular weight lignin nano-particles extracted from acid-assisted MIBK pretreatment. Polymers, 12(2), 1-12. 